\title{
Communication \\ Preprints in Chemistry: An Exploratory Analysis of Differences with Journal Articles
}

\author{
Mario Pagliaro
}

check for

updates

Citation: Pagliaro, M. Preprints in Chemistry: An Exploratory Analysis of Differences with Journal Articles. Publications 2021, 9, 5. https:// doi.org/10.3390/publications9010005

Received: 4 December 2020

Accepted: 29 January 2021

Published: 3 February 2021

Publisher's Note: MDPI stays neutral with regard to jurisdictional claims in published maps and institutional affiliations.

Copyright: (C) 2021 by the author. Licensee MDPI, Basel, Switzerland. This article is an open access article distributed under the terms and conditions of the Creative Commons Attribution (CC BY) license (https:// creativecommons.org/licenses/by/ $4.0 /)$.
Institute for the Study of Nanostructured Materials, Italian National Research Council (CNR), via U. La Malfa 153, 90146 Palermo, Italy; mario.pagliaro@cnr.it

\begin{abstract}
The exploratory analysis of the differences between preprints and the corresponding peer reviewed journal articles for ten studies first published on ChemRxiv and on Preprints, though statistically non-significant, suggests outcomes of relevance for chemistry researchers and educators. The full transition to open science requires new education of doctoral students and young researchers on scholarly communication in the digital age. The preliminary findings of this study will contribute to inform the curriculum of the aforementioned new courses for young chemists, eventually promoting accelerated innovation in a science that, unique amid all basic sciences, originates a huge industry central to the wealth of nations.
\end{abstract}

Keywords: preprints; preprints in chemistry; preprint servers; open science; ChemRxiv; chemistry preprint server; open access

\section{Introduction}

Publishing scientific articles in the form of "preprints" (though most preprints will never have a print version [1]), namely of freely accessible scientific documents posted on the internet before the peer review process, is rapidly replacing the conventional publishing process in several basic sciences. For instance, the publication rate of https://arxiv.org (arXiv), a website managed by the Library of Cornell University, in 2019 approached 13,000 preprints per month (12,989/month) [2]. Originally aimed at physics, mathematics and computer science scholars, arXiv currently hosts works also from quantitative biology, quantitative finance, statistics, electrical engineering, systems science and economics scholars. Similarly, the number of papers published by https:/ / www.biorxiv.org (bioRxiv), a preprint repository for the life sciences managed by Cold Springer Harbor Laboratory since late 2013, in October 2020 exceeded the 100,000 threshold, with a publication rate of 2943 preprints/month in the first eight months of 2020 [3].

In slightly more than three years since its debut (in May 2016) https: / /www.preprints. org (Preprints), the multidisciplinary preprint platform owned by the scientific publisher MDPI, reached the milestone of 10,000 preprints [4]. Yet, it took only 13 months to almost double the number of preprints to 17,000 by late October 2020. Showing the global impact of preprints, the latter studies at Preprints were co-authored by over 64,000 authors, whereas those at bioRxiv from close to 424,000 scholars.

We briefly remind that, in general, prior to publication of the preprint an editor working for the organization owning the preprint server checks the uploaded manuscripts for minimum quality and lack of plagiarism. Eventually, the manuscript authored with no requirements on how to write and structure the article is posted online as a PDF (portable document format) file, but also in HTML and XML formats by certain servers such as bioRxiv and Authorea so as to make data-rich preprints in HTML easily discovered by search engines, easily translated and readily "data mined".

Dubbed Chemistry Preprint Server (CPS), the first chemistry preprint server was launched in August 2000 at http:/ / preprint.chemweb.com. Two years later the CPS hosted already 500 preprints in numerous areas of chemistry, from biochemistry to computational 
chemistry [5], co-authored by scholars based in 51 different countries. Alas, the website chemweb.com was subsequently closed because "changes in search algorithms resulted in a dramatic decline in traffic and a corresponding drop in revenue" [6]. Other attempts to launch chemistry preprint servers from large publishing companies were unsuccessful [7].

Publishing their research work in the the most oligopolistic sector of the highly profitable scientific publishing industry [8], chemistry scholars were recently found to be those publishing with the lowest frequency in open access (OA) journals. In detail, the analysis of 100,000 recent articles from all disciplines found that less than $20 \%$ of the chemistry papers were freely accessible [9]. In this context, by August 2017 the American Chemical Society, joined by the Royal Society of Chemistry and the German Chemical Society, launched a new chemistry preprint server at https:// chemrxiv.org (ChemRxiv, today partly owned also by the Chemical Societies of Japan and of China). By late October 2020, the platform hosted 6422 preprints, with an average publication rate of 324 preprints/month recorded in the first eight months of 2020 [10]. By the same time, Preprints hosted close to 1000 chemistry preprints.

The question of how much papers change between preprint and final published article is important because it may aid to dispel myths surrounding preprints in scientific communities (like research chemists) still reluctant to their uptake, as well as to enhance trust of scholars in this new form of scientific publishing. One myth identified by Tennant and co-workers for example, is "the risk of 'scooping' often used to argue against preprints, whereas in reality the opposite is true as a preprint defines precedence and 'ownership' of research" [11]. Surveying 38 stakeholders based in eight European countries (from research funders through unengaged researchers), Chiarelli and collaborators recently reported that trust was "the essential factor in preprint posting" [12] with preprints creating "what might be called a trust barrier" [12].

Yet, in 2016, a first seminal study, comparing more than 12,000 arXiv preprints with the corresponding refereed journal articles, concluded that little differences exist between the preprint and peer reviewed articles when considering titles, abstracts and the body of the text (both on the semantic and on the editorial level) [13]. In addition, extending the same statistical analysis to 2500 preprints from bioRxiv revealed very little changes between the final published scientific papers and their preprint versions [14]. Similarly, a recent analysis of 56 preprints published by bioRxiv in 2016 found that, on average, the peer reviewed articles were of "higher quality of reporting" than preprints, but that the difference was small [15].

The following exploratory analysis looks at the differences between preprints and the corresponding peer reviewed journal articles for 10 studies first published as preprints in ChemRxiv and in Preprints.

\section{Methodology}

Ten preprints which underwent subsequent publication as peer reviewed articles in international scientific journals were selected, five from ChemRxiv (Table 1) and five from Preprints (Table 2). The preprints were selected because they represent different fields of today's chemical research: spectroscopy and electron microscopy, catalysis, natural products, nanochemistry, green chemistry, and scientific education in the context of the emerging circular economy.

In the following analysis, changes between a preprint and its corresponding peer reviewed article are considered minor when concerning only style, grammar or graphical aspects such as the format of a table. Changes are classified as significant when the peer reviewed article includes new data, new experimental details and new discussion of results not present in the previous preprint.

Each table includes the preprint title, the journal in which the peer reviewed article was eventually published and the current (2019) journal impact factor (JIF), a citation-based metric [16]. The number of unique views of the selected preprints by 23 October 2020 is also included. Comparison between each preprint and the corresponding journal study 
concerns title, abstract, text and references. The preprints are identified (numbered) with bold numbers, rather than referred to them by type in the following, in order to generalize the text for non-chemistry experts (i.e., for readers not familiar with chemical terms and processes).

Table 1. Selected ChemRxiv preprints and journal hosting the peer reviewed article.

\begin{tabular}{|c|c|c|c|}
\hline Preprint No. & $\begin{array}{l}\text { Year of Publication } \\
\text { (Number of Views) * }\end{array}$ & Title & Journal (JIF) \\
\hline 1 & $2019(3203)$ & $\begin{array}{l}\mathrm{N} \text {-Heterocyclic carbene-functionalized magic number } \\
\text { gold nanoclusters }\end{array}$ & Nature Chemistry (21.687) \\
\hline 2 & $2020(1525)$ & $\begin{array}{l}\text { Responsible Science, Engineering and Education for } \\
\text { Water Resource Recovery and Circularity }\end{array}$ & $\begin{array}{l}\text { Environmental Science: Water } \\
\text { Research E Technology (3.449) }\end{array}$ \\
\hline 3 & $2019(2369)$ & $\begin{array}{l}\text { SilverSil: A New Class of Antibacterial Materials of } \\
\text { Broad Scope }\end{array}$ & ChemistryOpen (2.370) \\
\hline 4 & $2018(4344)$ & $\begin{array}{c}\text { General Cyclopropane Assembly via Enantioselective } \\
\text { Redox-Active } \\
\text { Carbene Transfer to Aliphatic Olefin }\end{array}$ & Angewandte Chemie (12.959) \\
\hline 5 & $2018(60,352)$ & $\begin{array}{l}\text { The cryoEM method MicroED as a powerful tool for } \\
\text { small molecule structure determination }\end{array}$ & ACS Central Science (12.685) \\
\hline
\end{tabular}

Table 2. Selected chemistry preprints at Preprints and journal hosting the peer reviewed article.

\begin{tabular}{|c|c|c|c|}
\hline Preprint No. & $\begin{array}{l}\text { Year of Publication } \\
\text { (Number of Views) * }\end{array}$ & Title & Journal (JIF) \\
\hline 6 & $2018(710)$ & Single-Atom Catalysis: A Practically Viable Technology? & $\begin{array}{l}\text { Current Opinion in Green and } \\
\text { Sustainable Chemistry (5.165) }\end{array}$ \\
\hline 7 & 2018 (309) & $\begin{array}{l}\text { Nanoparticles and Single Atoms in Commercial } \\
\text { Carbon-Supported Platinum-Group Metal Catalysts }\end{array}$ & Catalysts (3.520) \\
\hline 8 & 2019 (297) & $\begin{array}{l}\text { High Yields of Shrimp Oil Rich in Omega-3 and } \\
\text { Carotenoids: Extending to Shrimp Waste the Circular } \\
\text { Economy Approach to Fish Oil Extraction }\end{array}$ & ACS Omega (2.870) \\
\hline 9 & $2020(93)$ & $\begin{array}{l}\text { Synthesis, Antimicrobial and Antioxidant Activities of } \\
\text { 2-Isoxazoline Derivatives }\end{array}$ & Molecules (3.267) \\
\hline 10 & $2018(928)$ & $\begin{array}{l}\text { Solvent Free-microwave Green Extraction of Essential } \\
\text { Oil from Orange Peel (Citrus sinensis L.): Effects on } \\
\text { Shelf Life of Flavored Liquid Whole Eggs during } \\
\text { Storage under Commercial Retail Conditions }\end{array}$ & $\begin{array}{l}\text { Journal of Food Measurement } \\
\text { and Characterization (1.648) }\end{array}$ \\
\hline
\end{tabular}

* Views by 23 October 2020. Source: Altmetric, 2020.

\section{Results and Discussion}

Table 3 lists changes across the ten selected studies between final published journal article and preprint. The time between preprint and journal article publication is also listed.

Upon acceptance for publication in different journals following peer review, most journal articles had the same title of the deposited preprints. Only in the case of preprint 8 posted at Preprints, the title of the corresponding journal article was shorter.

The abstracts of the preprints published in ChemRxiv and the corresponding journal articles were the same in three out of five cases. The journal article deriving from preprint 2 specified that the article derived from interaction with the members of the Association of Environmental Engineering and Science Professors in a workshop organized at the 2017 association conference. The journal article published after preprint 4 includes two minor writing style changes. 
Table 3. Changes across each of the ten selected studies between final published journal article and preprint and time between preprint and journal article publication.

\begin{tabular}{|c|c|c|c|c|}
\hline $\begin{array}{l}\text { Preprint } \\
\text { Identifier }\end{array}$ & Title & Abstract & Text & $\begin{array}{l}\text { Time between Preprint } \\
\text { and Journal Article }\end{array}$ \\
\hline 1 & No change & No change & No difference & 5 months \\
\hline 2 & No change & One change, minor & Minor difference, includes Author biographies & 2 months \\
\hline 3 & No change & No change & $\begin{array}{l}\text { Minor difference, three more references and longer } \\
\text { conclusions }\end{array}$ & 4 months \\
\hline 4 & No change & Two changes, minor & No change & 4 months \\
\hline 5 & No change & No change & $\begin{array}{l}\text { Minor change brief, brief post preprint text, and five } \\
\text { new references }\end{array}$ & 16 days \\
\hline 6 & No change & Two changes, minor & $\begin{array}{l}\text { Minor difference, three more references and longer } \\
\text { conclusions }\end{array}$ & 20 months \\
\hline 7 & No change & Two changes, minor & No change & 42 days \\
\hline 8 & $\begin{array}{l}\text { Minor change } \\
\text { (shortened) }\end{array}$ & Three changes, minor & $\begin{array}{l}\text { Minor change, five new references and slightly longer } \\
\text { conclusions }\end{array}$ & 4 months \\
\hline 9 & No change & No change & Minor change, five new Schemes and one new Figure & 25 days \\
\hline 10 & No change & Four changes, significant & $\begin{array}{l}\text { Noticeable change, more succinct presentation using } \\
\text { several new figures and schemes }\end{array}$ & 8 months \\
\hline
\end{tabular}

The abstract of the preprints published in Preprints and the final published journal articles was the same in two out of five cases, specifically for preprints $\mathbf{6}$ and $\mathbf{9}$ and the corresponding journal articles. In the case of preprint 10, the abstract of the journal article [17] was significantly shorter than that in the preprint. The abstract of the final published article [18] is longer and slightly more informative than that of preprint 7, similarly to what happens for the abstract of the journal article [19] when compared to that of preprint 8.

Little or no differences were found between the texts of the final journal articles and the preprints published in ChemRxiv months or weeks before. Preprint 1 even used the template of the subscription journal in which it was eventually published five months after the preprint. Interestingly, the study made freely accessible as preprint includes on each page the sentence "Submitted manuscript: confidential" [20].

Preprint 2 makes use of the template of the subscription journal in which it was published two months after publication of the preprint as open access (OA) document, with a table (Table 1) resulting of even higher readability (using colors) in the preprint [21] than in the peer reviewed article. In the case of preprint 3, the final article published four months after the preprint in an OA journal includes three more references and slightly longer conclusions [22].

Preprints $\mathbf{4}$ and $\mathbf{5}$ do not use a journal template, but their content is almost identical to the final published articles. Preprint 4 does not include page numbers [23] but embeds high resolution colored figures and schemes. Downloading the preprint from ChemRxiv, users would also download the Table of Contents graphics and the same 470-page long Supporting Information section found four months later in the final published article. When compared to the text of preprint 5 , the peer reviewed article published 16 days after the preprint [24] includes at the end of the article a brief "Post preprint addendum" and five more references.

The latter preprint was uploaded, approved and published on the same day (17 October 2018). The day before Angewandte Chemie published a manuscript [25] of a SwissGerman team reporting the invention of a similar method to obtain the molecular structure of microcrystalline molecular compounds via electron diffraction. The manuscript was received by the journal's editorial office on October 2, 2018.

Larger, though still not significant differences were noted between the selected preprints deposited at Preprints and the published journal articles. When compared to the text of preprint 6 , the final published article illustrates concepts through new re- 
search in a quickly developing field of chemistry, published in the literature in the long period of time (20 months) between the publication of the preprint and that of the journal article [26]. In the case of preprint 7 , the final published article was virtually identical to the preprint, unless for a minor mistake in the sequential order of the Figures in the preprint that was corrected in the journal article [18].

When compared to preprint 8, the peer reviewed article [19] had a substantially higher number of references ( $22 \mathrm{vs.} 17$ ) and a longer and more informative conclusions section. In comparison to preprint 9, the final published article [27] includes five new schemes and one new figure. The experimental section and the conclusions are identical.

The largest differences in the present analysis were noted between preprint $\mathbf{1 0}$ and the corresponding journal article [17]. The latter embeds a more succinct presentation, with only four tables in the journal article vs. six in the preprint. Furthermore, the journal article includes as figure 1 an elegant and highly explanatory image displaying the experimental design, and as figure 2 an image showing electron microscopic pictures of treated and non-treated orange peels. Both figures were absent in the preprint. Finally, the journal article includes a richer conclusion section.

Published between 2018 and 2020, by 23 October 2020 all selected preprints but one had more than 100 reads (unique views). In general, the number of views was significantly higher for preprints published in ChemRxiv. For comparison, the most viewed preprint at Preprints among those selected herein had 928 views whereas the most viewed preprint at ChemRxiv had 60,352 views. In general, by the same date the most viewed preprint published by the multidisciplinary Preprints server had 5369 views. ${ }^{1}$

The high number of reads for preprints posted at ChemRxiv was noted since the early days of the preprint server, when a manager of the OA program of the ACS was "pleasantly surprised" [28] by the fact that by June 12, 2018, the 400 preprints posted had about 378,000 downloads/views. The trend continued, and two years later the editor of the online publishing platform remarked how preprints at ChemRxiv had been accessed "more than 10 million times, with upwards of 250,000 visitors to the site each day" [29].

\section{Outlook and Perspectives}

The exploratory and statistically non-significant analysis (due to the small sample size of the sample studied) reported in this study offers preliminary evidence that in chemistry, likewise to what happens in physics [13] and in the life sciences [14,15], the differences between preprints and the corresponding articles published after peer review are small. The preprints selected represent widely different fields of today's chemical research, from spectroscopy and electron microscopy through catalysis, natural products, nanochemistry, green chemistry and even scientific education. A statistical analysis including a much larger sample is needed to corroborate or confute these preliminary findings. Though preliminary and aware of this limitation, the study offers a few outcomes of relevance to today's chemistry scholars interested in the adopting open science practices given that, along with "green" self-archiving research articles on institutional or personal websites [30], the adoption of preprint is an essential part of the practice of open science [31].

Today, chemists can publish their work in preprint form on several preprint servers including ChemRxiv, Preprints, SSRN, Authorea, ResearchSquare, Zenodo, Beilstein Archives, OSF Preprints, ResearchGate and many others. Though being the community with the lowest uptake of preprints when compared to life scientists, physicists, computer scientists and mathematicians, chemistry scholars massively read preprints. For example, by late October 2020 about 6500 preprints posted on ChemRxiv had close to 13.5 million views. For comparison, a highly read OA chemistry journal such as Molecules recorded 13.8 million reads for 26,563 articles published by late December 2020 [32]. Furthermore, preprints deposited at ChemRxiv that had been cited 430 times in 2019 and 85 times in 2018, in 2020 started to be cited at a fast rate with close to 1050 citations in the first 10 months

1 www.preprints.org/subject/browse/chemistry?filter=most_viewed 
of the year. ${ }^{2}$ The reason explaining why research chemists eagerly read preprints may be that by doing so they learn new outcomes of relevance to their research several months ahead of time. Indeed, even in 2013 when virtually all chemistry journals were published on the internet, the average publication time (submitted to published time) for chemistry manuscripts was nine months (and four and a half months for submitted to accepted) [33].

Following studies and even experiments with reviewers concerning the peer review process carried out when he was editor of a prestigious medical journal, Smith in 2006 concluded that peer review "is a flawed process, full of easily identified defects with little evidence that it works" [34]. Hence, rather than striving to publish their work in peer reviewed journals of high impact factor, young chemistry researchers should be aware that the JIF is a poor statistical indicator imposed by a very small number of highly cited papers (for which most papers published in high impact factor journals actually get fewer citations than indicated by the JIF) [35]. On the other hand, by making their work freely and immediately accessible on the internet first in the form of preprints and subsequently in the form of peer reviewed journal articles in OA or paywalled journals, chemistry scholars too will rapidly reap the benefits of open science already demonstrated in closely related disciplines (life sciences and physics) in terms of enhanced citations, media attention, collaborations, job and funding opportunities [36].

Additionally for chemistry researchers, the fairer evaluation of scholarship [37] today includes several indicators beyond citations collectively called alternative metrics ("altmetrics", for which even an international OA journal was established in 2018). ${ }^{3}$ The number of reads (views) and downloads of each preprint, for example, is a clear indication of interest of the scholarly community. The preprint anticipating the almost concomitant discovery of a new method to obtain the molecular structure of microcrystalline molecular compounds via electron diffraction received by January 2021 an Altmetric "attention score" of 686 [38], which rank the preprint in the top 5\% of all research outputs scored by Altmetric so far.

A few economic figures may help to explain why chemistry scholars showed reluctance to adopt open science practices, including publishing their work in preprint form after the early successful attempts with the Chemistry Preprint Server [5]. It is enough to ask even a prolific author in the chemical sciences if she/he knows what the cost paid is by her/his institution's library to access articles published by a typical subscription-based chemistry journal; and what is the market concentration level of the publishing industry in the chemical sciences. Most often, she/he will be generally surprised to learn that chemistry has historically recorded the highest average journal serial prices [39], and that in 2020 the average price for chemistry journals was the highest amid all disciplines, exceeding the $\$ 6300$ threshold (Table 4). For comparison, in 2016 the average price for chemistry journals was $\$ 5105$ [40]. Similarly, a few chemistry scholars are aware that only five publishers control publishing of more than $70 \%$ of chemistry studies [8].

Table 4. Average journal price by discipline in 2020. Top five ranking. [Source: Library Journal Periodicals Price Survey, 2020].

\begin{tabular}{ccc}
\hline Rank & Discipline & Price (in \$) \\
\hline 1 & Chemistry & 6316 \\
2 & Physics & 5137 \\
3 & Engineering & 4218 \\
4 & Biology & 3977 \\
5 & Food science & 3414 \\
\hline
\end{tabular}

I agree with Polka [41] and with other open science researchers [42] who found that the key challenge for the transition to open science is cultural change. To effectively foster said cultural change, in its turn, chemistry scholars and educators need to expand

\footnotetext{
Source: Scopus, October 2020.

Journal of Altmetrics
} 
the education of doctoral students and young researchers to include scholarly communication in the digital age [43]. The preliminary findings of this study will contribute to inform the curriculum of the aforementioned new courses for young chemists, eventually promoting accelerated innovation in chemistry [44] and the associated social, economic and environmental benefits due to the fact that chemistry, unique amid all basic sciences, originates a huge global industry central to the wealth of every nation hosting chemical productions [45].

Funding: This research received no external funding.

Institutional Review Board Statement: Not applicable.

Informed Consent Statement: Not applicable.

Data Availability Statement: All data are available by contacting the author.

Conflicts of Interest: The author declares no conflict of interest.

\section{References}

1. Bourne, P.E.; Polka, J.K.; Vale, R.D.; Kiley, R. Ten simple rules to consider regarding preprint submission. PLoS Comput. Biol. 2017, 13, e1005473. [CrossRef] [PubMed]

2. Cornell University. arXiv Submission Rate Statistics. 2020. Available online: https://arxiv.org/help/stats/2019_by_area/index (accessed on 23 November 2020).

3. Rxivist. Site-Wide Metrics. 2020. Available online: https:/ / rxivist.org/stats (accessed on 23 November 2020).

4. Preprints. Preprints Reaches 10,000 Posted Articles Milestone. 5 August 2019. Available online: https://www.preprints.org/ announcement/show /37 (accessed on 23 November 2020).

5. Town, B. A preprint server for chemistry. Chem. Int. 2002, 24, 14-15. [CrossRef]

6. Chemweb. Available online: https://chemweb.com/ (accessed on 23 November 2020).

7. Demma Carà, P.; Ciriminna, R.; Pagliaro, M. Has the time come for preprints in chemistry? ACS Omega 2017, 2, 7923-7928. [CrossRef] [PubMed]

8. Larivière, V.; Haustein, S.; Mongeon, P. The oligopoly of academic publishers in the digital era. PLoS ONE 2015, 10, e012750. [CrossRef]

9. Piwowar, H.; Priem, J.; Larivière, V.; Alperin, J.; Matthias, P.L.; Norlander, B.; Farley, A.; West, J.; Haustein, S. The state of OA: A large-scale analysis of the prevalence and impact of open access articles. Peer J. 2018, 6, e4375. [CrossRef]

10. GitHub. ChemRxiv Dashboard. 2020. Available online: https://chemrxiv-dashboard.github.io (accessed on 23 November 2020).

11. Tennant, J.; Bauin, S.; James, S.; Kant, J. The evolving preprint landscape: Introductory report for the knowledge exchange working group on preprints. MetaArXiv 2018. [CrossRef]

12. Chiarelli, A.; Johnson, R.; Pinfield, S.; Richens, E. Preprints and scholarly communication: An exploratory qualitative study of adoption, practices, drivers and barriers. F1000Res 2019, 8, 971. [CrossRef]

13. Klein, M.; Broadwell, P.; Farb, S.E.; Grappone, T. Comparing published scientific journal articles to their pre-print versions. arXiv 2016, arXiv:1604.05363.

14. Klein, M.; Broadwell, P.; Farb, S.E.; Grappone, T. Comparing published scientific journal articles to their pre-print versions. Int. J. Digit. Libr. 2019, 20, 335-350. [CrossRef]

15. Carneiro, C.F.D.; Queiroz, V.G.S.; Moulin, T.C.; Carvalho, C.A.M.; Haas, C.B.; Rayêe, D.; Henshall, D.E.; De-Souza, E.A.; Amorim, F.E.; Boos, F.Z.; et al. Comparing quality of reporting between preprints and peer-reviewed articles in the biomedical literature. bioRxiv 2020, 581892. [CrossRef]

16. Bornmann, L.; Marx, W. The journal impact factor and alternative metrics. EMBO Rep. 2016, 17, 1094-1097. [CrossRef] [PubMed]

17. Aboudaou, M.; Ferhat, M.A.; Hazzit, M.; Ariño, A.; Djenane, D. Solvent free-microwave green extraction of essential oil from orange peel (C. sinensis L.): Effects on shelf life of flavored liquid whole eggs during storage under commercial retail conditions. J. Food Meas. 2019, 13, 3162-3172. [CrossRef]

18. Petek, U.; Ruiz-Zepeda, F.; Bele, M.; Gaberšček, M. Nanoparticles and single atoms in commercial carbon-supported platinumgroup metal catalysts. Catalysts 2019, 9, 134. [CrossRef]

19. Scurria, A.; Fabiano Tixier, A.-S.; Lino, C.; Pagliaro, M.; D’Agostino, F.; Avellone, G.; Chemat, F.; Ciriminna, R. High yields of shrimp oil rich in Omega-3 and natural astaxanthin from shrimp waste. ACS Omega 2020, 5, 17500-17505. [CrossRef] [PubMed]

20. Narouz, M.R.; Osten, K.M.; Unsworth, P.J.; Man, R.W.Y.; Salorinne, K.; Takano, S.; Tomihara, R.; Kaappa, S.; Malola, S.; Dinh, C.T.; et al. N-heterocyclic carbene-functionalized magic number gold nanoclusters. ChemRxiv 2018. [CrossRef] [PubMed]

21. Weissbrodt, D.G.; Winkler, M.K.H.; Wells, G.F. Responsible science, Engineering and education for water resource recovery and circularity. ChemRxiv 2020. [CrossRef]

22. Trabelsi, K.; Ciriminna, R.; Albo, Y.; Pagliaro, M. SilverSil: A new class of antibacterial materials of broad scope. ChemistryOpen 2020, 9, 459-463. [CrossRef] 
23. Montesinos-Magraner, M.; Costantini, M.; Ramirez-Contreras, R.; Muratore, M.E.; Johansson, M.J.; Mendoza, A. General cyclopropane assembly via enantioselective redox-active carbene transfer to aliphatic olefin. ChemRxiv 2018. [CrossRef]

24. Jones, C.G.; Martynowycz, M.W.; Hattne, J.; Fulton, T.J.; Stoltz, B.M.; Rodriguez, J.A.; Nelson, H.; Gonen, T. The CryoEM method MicroED as a powerful tool for small molecule structure determination. ACS Centr. Sci. 2018, 4, 1587-1592. [CrossRef]

25. Gruene, T.; Wennmacher, J.T.C.; Zaubitzer, C.; Holstein, J.J.; Heidler, J.; Fecteau-Lefebvre, A.; De'Carlo, S.; Müller, E.; Goldie, K.N.; Regeni, I.; et al. Rapid structure determination of microcrystalline molecular compounds using electron diffraction. Angew. Chem. Int. Ed. Engl. 2018. [CrossRef]

26. Ciriminna, R.; Pagliaro, M.; Luque, R. Heterogeneous catalysis under flow for the 21st century fine chemical industry. Green Energy Environ. 2021. [CrossRef]

27. Alshamari, A.; Al-Qudah, M.; Hamadeh, F.; Al-Momani, L.; Abu-Orabi, S. Synthesis, antimicrobial and antioxidant activities of 2-isoxazoline derivatives. Molecules 2020, 25, 4271. [CrossRef] [PubMed]

28. Henderson, D.; Lawlor, B. In preprints and scholarly communication. Chem. Int. 2018, 40, 18-21. [CrossRef]

29. Brennan, M. Hindawi, Streamlining Chemistry Preprints to Peer Review. 8 June 2020. Available online: www.hindawi.com/post/ streamlining-chemistry-preprints-peer-review (accessed on 2 February 2021).

30. Vincent-Lamarre, P.; Boivin, J.; Gargouri, Y.; Larivière, V.; Harnad, S. Estimating open access mandate effectiveness: The MELIBEA score. J. Assoc. Inf. Sci. Technol. 2016, 67, 2815-2828. [CrossRef]

31. Green, T. Is open access affordable? Why current models do not work and why we need internet-era transformation of scholarly communications. Learn. Publ. 2019, 32, 13-25. [CrossRef]

32. MDPI. Molecules Statistics. Available online: https://www.mdpi.com/journal/molecules/stats (accessed on 28 December 2020).

33. Björk, B.-C.; Solomon, D. The publishing delay in scholarly peer-reviewed journals. J. Informetr. 2013, 7, 914-923. [CrossRef]

34. Smith, R. Peer review: A flawed process at the heart of science and journals. J. R. Soc. Med. 2006, 99, 178-182. [CrossRef]

35. Larivière, V.; Kiermer, V.; MacCallum, C.J.; McNutt, M.; Patterson, M.; Pulverer, B.; Swaminathan, S.; Taylor, S.; Curry, S. A simple proposal for the publication of journal citation distributions. bioRxiv 2016, 062109. [CrossRef]

36. McKiernan, E.C.; Bourne, P.E.; Brown, C.T.; Buck, S.; Kenall, A.; Lin, J.; McDougall, D.; Nosek, B.A.; Ram, K.; Soderberg, C.K.; et al. How open science helps researchers succeed. eLife 2016, 5, e16800. [CrossRef]

37. American Society for Cell Biology. The San Francisco Declaration on Research Assessment (DORA). 2013. Available online: https://sfdora.org/read/ (accessed on 2 February 2021).

38. Altmetric. The CryoEM Method MicroED as a Powerful Tool for Small Molecule Structure Determination. Overview of Attention for Research Output Published on ChemRxiv. Available online: https:/ /www.altmetric.com/details/49844881 (accessed on 20 January 2021).

39. Bosch, S.; Albee, B.; Romaine, S. Costs Outstrip Library Budgets. Periodicals Price Survey 2020. Libr. J. 2020. Available online: www.libraryjournal.com/?detailStory=Costs-Outstrip-Library-Budgets-Periodicals-Price-Survey-2020 (accessed on 2 February 2021).

40. Bosch, S.; Henderson, K. Fracking the Ecosystem. Periodicals Price Survey 2016. Libr. J. 2016. Available online: www. libraryjournal.com/?detailStory=fracking-the-ecosystem-periodicals-price-survey-2016 (accessed on 2 February 2021).

41. Polka, J. Promoting a culture of preprinting in biology. In Proceedings of the CERN-UNIGE Workshop on Innovations in Scholarly Communication, Geneva, Switzerland, 21-23 June 2017. Available online: https:/ / indico.cern.ch/event/405949/contributions / 2487847 / (accessed on 2 February 2021).

42. Ignat, T.; Ayris, P. Built to last! Embedding open science principles and practice into European universities. Insights 2020, 3, 9. [CrossRef]

43. Pagliaro, M. Publishing scientific articles in the digital era. Open Sci. J. 2020, 5, 3. [CrossRef]

44. Pagliaro, M. Chemistry education fostering creativity in the digital era. Isr. J. Chem. 2019, 59, 565-571. [CrossRef]

45. Pagliaro, M. An industry in transition: The chemical industry and the megatrends driving its forthcoming transformation. Angew. Chem. Int. Ed. 2019, 58, 11154-11159. [CrossRef] [PubMed] 